ARTIGOS 



\title{
O Trabalho Escravo Contemporâneo e os Usos da História ${ }^{0^{*}}$
}

\author{
Rebecca J. Scott ${ }^{* *_{1}}$
}

\begin{abstract}
Resumo: O uso da palavra "escravidão" para descrever várias formas contemporâneas de exploração suscita questões de definição legal. A escravidão nas Américas no século dezenove estava ancorada na reivindicação de propriedade sobre pessoas, portanto usar o termo para caracterizar abusos modernos, quando nenhum Estado reconhece mais a propriedade sobre pessoas, pode representar um risco de anacronismo. Em debates parlamentares recentes, tanto na França quanto no Brasil, a acusação de anacronismo foi feita pelos opositores do reconhecimento legal do crime de escravização. Evidências históricas demonstram, entretanto, que o exercício dos poderes inerentes ao direito de propriedade não necessariamente derivam de um prévio direito legal à propriedade. O controle sobre pessoas, equivalente à posse, podia ocorrer fora da lei e no entanto ser reconhecido como propriedade legal após o fato. Na justaposição de um caso de 1810, de Nova Orleans, na Louisiana, com a situação que deu origem à decisão do caso Siliadin contra França pela Corte Europeia de Direitos Humanos, esse artigo analisa os paralelos nas circunstâncias de escravidão urbana e os mecanismos através dos quais os "poderes inerentes ao direito de propriedade" foram exercidos, independente de qualquer direito de fato. $\mathrm{O}$ argumento apoia tanto a reforma do código penal francês para tornar o crime de escravização explícito, e a emenda proposta à Constituição brasileira que elevaria as penas para o uso de trabalho escravo.
\end{abstract}

Palavras-chave: escravidão contemporânea, direitos inerentes ao direito de propriedade, França, Brasil, São Domingos, Corte Europeia de Direitos Humanos, Siliadin contra França

\footnotetext{
Abstract: The use of the word "slavery" to describe various contemporary forms of exploitation raises questions of legal definition. Slavery in the 19th century Americas was rooted in the claim of property in persons, so using the term to characterize modern abuses, when no state any longer recognizes the ownership of persons, seems to pose a risk of anachronism. During recent parliamentary debates in both France and Brazil, the charge of anachronism has been levied by opponents of the explicit recognition in law of a criminal offense of enslavement. Historical evidence demonstrates, however, that the exercise of the powers attaching to a right

* Copyright pela autora, 2013.

** Departamento de História e Faculdade de Direito, University of Michigan. Contato: rjscott@umich.edu

1 Agradeço a meus colegas Beatriz Mamigonian, Silvia Hunold Lara, Mariana Dias Paes e Leonardo Barbosa por sua ajuda na preparação dessa tradução. As fontes documentais e arquivísticas para este ensaio podem ser encontradas no meu artigo "Under Color of Law: Siliadin vs France and the Dynamics of Enslavement in Historical Perspective". In: Jean Allain (ed.). The Legal Understanding of Slavery: From the Historical to the Contemporary. Oxford: Oxford University Press, 2012. Acesso em: http://papers.ssrn.com/ abstract $=2292681$
} 
of ownership did not, in fact, necessarily derive from a prior legal right of ownership. Control over persons, tantamount to possession, could occur quite outside the law, though it might be cognized as legal ownership after the fact. Juxtaposing an episode from New Orleans in 1810 with the situation that gave rise to the 2005 European Court of Human Rights decision in Siliadin contra France, the paper analyzes the parallels in the circumstances of urban slavery, and the mechanisms by which "powers attaching to a right of ownership" came to be exercised, quite independent of any actual right. The argument thus supports both the proposed 2013 reforms to the French penal code that would make the crime of enslavement explicit, and the proposed amendment to the Brazilian Constitution that would raise the penalties for the use of slave labor.

Keywords: contemporary slavery, powers attaching to the right of ownership, France, Brazil, Saint-Domingue, European Court of Human Rights, Siliadin v. France

No Brasil, como em outros países, as campanhas contra o trabalho escravo são frequentemente confrontadas com questões complexas de definição. Alguns juízes evitam usar a palavra "escravidão", alegando que esse termo implica condições de sujeição absoluta, em que uma pessoa seria propriedade de outra. É comum encontrar a ideia de que a escravidão envolve grilhões e chicotes, e que a palavra "escravo" não pode ser aplicada a uma pessoa que é juridicamente livre e formalmente capaz de sair do lugar em que trabalha.

Os que se opõem à criminalização da exploração do trabalho escravo, e à expropriação de propriedades em que o uso de trabalho escravo for confirmado, usam o argumento de que a definição legal de uma situação de escravidão não é clara e que as medidas previstas pela Proposta de Emenda Constitucional atualmente em debate no Senado abririam a possibilidade de abusos por parte de fiscais ou procuradores. Assim, em vez de examinar os parâmetros bem concretos usados por procuradores e fiscais que atuam nessa área, preferem apenas sugerir que a definição de "trabalho escravo" ainda é bastante abstrata e controvertida.

Sabemos todos que esses argumentos são frequentemente movidos pela má fé e pelo desejo de lucro. Para fazer frente a esses problemas e questionamentos, no entanto, é importante que juristas e outras pessoas que lidam com essa temática levem a sério a questão da definição. Este artigo propõe uma contribuição histórica para esse esforço de esclarecimento.

Como definir "escravidão" ou "trabalho escravo"? O que fazia de alguém um escravo no século XIX, quando a escravidão era uma instituição reconhecida e identificada com a propriedade sobre as pessoas? Como definir alguém como escravo, com alguma precisão, no século XXI, quando a propriedade sobre pessoas não é admitida pela lei? À primeira vista, pode-se imaginar que o termo "escravo" no século XIX significava uma pessoa sobre a qual havia um verdadeiro direito de propriedade; e seria, portanto, enganoso usar o termo no século XXI, pois não há nenhum legítimo direito de propriedade sobre pessoas em um mundo em que a escravidão foi abolida.

Mas, quando examinamos os textos produzidos pela Liga das Nações e pelas Nações Unidas, e outros documentos pertinentes ao tema, vemos que a escravidão é definida no direito internacional do seguinte modo: "o estado ou a condição de um indivíduo sobre o qual se exercem, total ou parcialmente, alguns ou todos os atributos do direito de propriedade". É importante observar que a formulação não fala em 
«propriedade», mas em «atributos do direito de propriedade». Talvez seja útil pensar nesta definição como uma fórmula algébrica: o exercício de poderes - abre parênteses - inerentes ao direito de propriedade - fecha parênteses - sobre uma pessoa.

Em outras palavras, existem poderes que são inerentes à propriedade e, se esses poderes são exercidos sobre uma pessoa - mesmo que ela não seja propriedade de ninguém -, a relação pode, no direito internacional, ser descrita juridicamente como de escravidão. Em algumas decisões recentes, vários tribunais têm reconhecido a utilidade dessa definição (que data de 1926, feita pela Liga das Nações) e considerado que se pode compreender vários abusos cometidos tanto em tempos de guerra quanto de paz como escravidão. Mas, se separamos o exercício desses poderes do título de propriedade, propriamente dito, por que usar a palavra "escravidão"? Não seria um anacronismo, já que a palavra "escravidão", desde pelo menos a época do Império Romano, se refere à propriedade de pessoas?

Para demonstrar por que não é assim, é importante tratar de exemplos específicos, deixando de lado por um momento as questões abstratas.

Podemos examinar as histórias de duas mulheres, uma chamada Adélaïde Métayer e outra Henriette Akofa Siliadin, para esclarecer a relação entre escravidão e condição social. Cada uma delas se viu em uma cidade desconhecida, em busca de segurança e de novas oportunidades, mas foi confrontada com a perspectiva ou a realidade da escravização. Cada uma delas procurou o Judiciário para garantir uma liberdade duradoura e para obter proteção jurídica para o que elas acreditavam ser seus direitos.

Essas duas mulheres viveram separadas por 200 anos e por um oceano. Analisá-las lado a lado pode parecer uma estratégia estranha, pois nós historiadores evitamos o anacronismo a todo custo. Mas a justaposição de eventos tão distantes no tempo torna-se inevitável diante do uso dos termos "escravidão" e "trabalho escravo" nos textos sobre direitos humanos, no discurso público, e, no caso do Brasil, nos textos sobre o Direito do Trabalho e sobre a Proposta de Emenda Constitucional (PEC) n. 438/01, agora denominada, no Senado, PEC n. 57A/1999.

Vejamos, então, como o direito, no século XIX, discernia se alguém era ou não escravo, examinando o caso de Adélaïde Métayer. Ela nasceu de mãe escrava, em 1780, na cidade de Cap Français, São Domingos, na época em que a colônia estava sob o domínio do antigo regime francês. Adélaïde era muito jovem durante a grande insurreição escrava de 1791. Seu proprietário, um alfaiate chamado Charles Métayer, fugiu da colônia com sua mulher, provavelmente em 1793, quando Adélaïde tinha mais ou menos 13 anos de idade. O casal a manteve como escrava e se fixou em Nova lorque.

Enquanto isso, em São Domingos, a revolução colocou fim à escravidão na colônia francesa, agora sob o poder de Toussaint Louverture, ele mesmo um ex-escravo que havia se tornado governador geral e comandante do exército de São Domingos, ainda sob a bandeira francesa. Louverture ofereceu aos que haviam se refugiado em outros países a possibilidade de voltarem e retomarem suas propriedades - exceto a propriedade sobre as pessoas, que havia sido abolida. Charles Métayer e sua mulher retornaram para Cap Français, com Adélaïde.

Parecem ter conseguido que Adélaïde continuasse a trabalhar para eles por um tempo, talvez protegidos por uma medida que obrigava alguns ex-escravos domésticos a ficarem empregados com seus antigos donos. Mas Adélaïde, que agora tinha um filho pequeno, viu que as pessoas à sua volta estavam livres e tentou sair da casa dos Métayer. Ela ofereceu dinheiro a eles, para obter um reconhecimento por escrito de sua liberdade. Em 1801, Charles Métayer aceitou o dinheiro e 
deu a Adélaïde um recibo que atestava sua liberdade. Mas Charles não queria deixar que ela levasse o filho consigo, e disse que o libertaria mais tarde, "graciosamente".

Adélaïde trabalhou por um tempo como vendedora e viveu com um homem empregado nos fornos de cal. Porém, quando Napoleão Bonaparte enviou uma força expedicionária da França para tirar Toussaint Louverture do poder, a colônia foi tomada pela guerra. A autonomia de Louverture nas relações internacionais e a insistência em acabar com a escravidão tinham enfurecido Bonaparte, que estava determinado a retomar o controle direto sobre a colônia e restaurar a escravidão.

As tropas napoleônicas não conseguiram restaurar nem a escravidão, nem o controle colonial, mas produziram uma catástrofe humana, espalhando a guerra pelo território e forçando a fuga de dezenas de milhares de pessoas, que se refugiaram em portos seguros mais próximos. Adélaïde estava entre esses refugiados. Ela possuía o papel que atestava sua liberdade, tinha recuperado a custódia de seu filho, e conseguiu lugar num navio para a Jamaica.

Por volta de 1805, ela chegou a Baracoa, em Cuba. Milhares de refugiados de São Domingos já tinham fugido diretamente para Cuba em 1803; entre eles vários dos vizinhos de Adélaïde. Em Cuba, alguns dos refugiados, abusando da vulnerabilidade de outros, haviam conseguido impor o exercício de poderes que correspondem ao direito de propriedade. E, uma vez estabelecida tal relação social, o direito espanhol simplesmente reconheceu este fato social como prova do direito de propriedade. Os "criados" se tornaram "escravos" e a reescravização foi concluída.

Porém, todas as testemunhas que depuseram no processo de Adélaïde concordavam que ela tinha vivido como mulher livre em Baracoa. Ali, ela tinha dado à luz duas filhas e, no momento do batismo de cada uma delas, havia mostrado o recibo assinado por Métayer que reconhecia sua "liberdade," e as meninas haviam sido batizadas como livres.

Entretanto, em 1808, a guerra na Europa entre a França e a Espanha levou à expulsão dos refugiados vindos de São Domingos da colônia de Cuba, pois eram percebidos como "franceses". Adélaïde juntou-se a uma outra migração força$\mathrm{da}$, dessa vez para a Louisiana. Os navios chegaram ao porto de Nova Orleans às dezenas, levando quase dez mil refugiados de São Domingos como passageiros. Ainda que a abolição da escravidão em São Domingos tivesse extinguido todo o direito de propriedade sobre pessoas, a passagem pelas águas do Caribe e do Golfo tinha permitido aos mais poderosos dentre os refugiados impor sua vontade sobre outros. Uma vez estabelecida tal relação de força, os oficiais da Louisiana entenderam a situação como escravidão. Assim, no momento em que entraram na Louisiana, 3.226 pessoas que haviam sido emancipadas pela revolução haitiana, uma emancipação que fora ratificada pela Assembleia Nacional da França, foram registradas como escravas.

Mais uma vez, Adélaïde evitou esse destino. Era uma mulher confiante, segura de si, que já em Cuba desafiava qualquer um que ousasse se referir a ela como escrava. Ela e suas três crianças se fixaram na comunidade de refugiados, que incluía gente que ela conhecia desde o tempo em que vivia em Cap Français. Um deles era um alfaiate francês chamado Louis Noret, que havia sido sócio do antigo senhor de Adélaïde. Ela tinha confiança em Noret, tanto que deu o recibo de Charles Métayer que provava sua liberdade para que ele o guardasse em lugar seguro. Em princípio, parecia lógico: Noret parecia um homem branco honesto que poderia levar a prova de sua liberdade para as autoridades, em caso de necessidade. Na prática, entretanto, não foi uma boa ideia.

Em março de 1810, o alfaiate Noret ajuizou uma ação e, afirmando que a familia do antigo senhor de Adélaïde tinha uma dívida com ele, pediu permissão para 
apreender qualquer "propriedade" da família Métayer que pudesse ser encontrada em Nova Orleans. Ele conseguiu a autorização e, junto com o xerife, foi ao alojamento de Adélaïde e apreendeu-a com suas três crianças.

Nas semanas seguintes, o jornal local publicou um anúncio dizendo que Adélaïde e seus filhos seriam leiloados nos degraus do Café da Bolsa, em 28 de maio de 1810, para liquidação da dívida no processo de Noret contra Métayer. No último minuto, Adélaïde conseguiu obter os serviços de um advogado e entrou com um processo contra Noret para suspender sua apreensão.

Nesse ponto é que chegamos bem perto da questão de como o estatuto de escravo foi julgado - ou seja, como o direito determinava se uma pessoa era escrava ou livre. $O$ advogado de Adélaïde não argumentou que ela era livre como resultado da revolução haitiana e da abolição da escravidão pela Assembleia Nacional francesa, que tinha extinguido todo o direito de propriedade sobre pessoas. Essa abolição era bem conhecida de todos, mas na cidade de Nova Orleans, onde a posse escrava era generalizada, seria imprudente defender a liberdade concedida por Toussaint Louverture e seu exército revolucionário de ex-escravos. Em vez disso, o advogado apresentou como prova de sua liberdade uma cópia do recibo que Charles Métayer havia dado a Adélaïde quando ela pagou pelo fim dos serviços que ele lhe exigia.

Mas o recibo era datado de $1801 . .$. e que idade tinha seu filho? Adélaïde primeiro tentou argumentar que o menino tinha nove anos, tendo nascido, portanto, quando ela já era livre, depois de obter o recibo que apresentava como um "papel de liberdade". Depois, admitiu que a criança tinha 11 anos e tinha nascido antes da data do papel de liberdade.

A venda de Adélaïde e de suas filhas foi adiada enquanto o juiz julgava sua reivindicação de liberdade. O menino, no entanto, como estava previsto, foi posto em leilão. Nascido livre depois da abolição em São Domingos, o filho de Adélaïde foi considerado escravo em Louisiana porque sua mãe não tinha nenhum documento que mencionasse especificamente o seu nome, atestando sua liberdade.

Como a venda do garoto acabou cobrindo a dívida que Noret tinha declarado, o caso de Adélaïde contra Noret não foi julgado. Uma vez que a dívida foi paga, o processo judicial ficou parado. Adélaïde e suas filhas voltaram para casa, mas seu estatuto ficou sem definição.

Mesmo assim, quando em 1816 Adélaïde deu à luz outro menino, no registro do batismo ela aparece de novo como uma "mulata livre." No entanto, já que a possibilidade de reivindicar o direito de propriedade sobre Adélaïde tinha dado dinheiro a Noret uma vez, com a venda do filho mais velho, Noret estava decidido a tentar novamente. Depois de localizar o herdeiro do antigo dono de Adélaïde e conseguir dele uma procuração, Noret recomeçou sua campanha para controlar Adélaïde. Ajuizou um processo em que reclamava a propriedade sobre ela, em nome do herdeiro de Charles Métayer.

É fácil constatar como é complexa a questão do estatuto de Adélaïde. Ela vivia como mulher livre, mas era confrontada por pessoas que atuavam como proprietários dela, sem que tivessem qualquer título de propriedade — pois toda a propriedade sobre pessoas fora abolida em 1794, em São Domingos, jurisdição de onde eles todos tinham vindo, tanto os supostos proprietários como a suposta escrava.

Adélaïde vivia no período clássico da escravidão, mas existia em algum lugar dessa cena "um verdadeiro direito de propriedade" sobre Adélaïde? E, mais importante, havia um legítimo direito de propriedade sobre os 3.226 refugiados de São Domingos, que eram todos livres segundo a lei francesa desde a década de 1790, 
mas que haviam sido reescravizados na chegada a Cuba ou na chegada a Nova Orleans? Esses três mil e tantos homens e mulheres foram mantidos como escravos. Os poderes inerentes ao direito de propriedade foram exercidos sobre eles, tenha sido esse direito de propriedade (em algum sentido) válido ou falso, reconhecido ou não.

Deixemos de lado por um momento o caso de Adélaïde Métayer, para darmos uma olhada rápida no caso de Henriette Siliadin, ocorrido mais de 180 anos depois - um caso que envolve a jurisprudência internacional de direitos humanos.

Iwa Akofa Siliadin nasceu no Togo, na África Ocidental. Tinha 15 anos em 1994, quando a irmã de uma amiga da família ofereceu-se para levá-la para Paris, prometendo matriculá-la na escola e ajuda para a obtenção do visto de residência. Iwa Akofa era uma adolescente e sua família tinha dificuldades; a perspectiva de ir para Paris era interessante. Ela acompanhou a mulher e entrou na França com um visto de turista, para uma estadia curta.

Logo ficou claro, entretanto, que a oferta de matrícula na escola tinha sido uma artimanha. A mulher colocou Iwa Akofa, agora chamada de Henriette, para trabalhar como babá e para limpar a casa. As coisas pioraram quando essa conhecida "emprestou" Henriette para outra família, para realizar os mesmos afazeres.

A nova família a mantinha sob restrições ainda maiores e sob rígida vigilância no apartamento em que moravam em Paris. Confiscou seu passaporte e ameaçou-a dizendo que a polícia a prenderia se ela tentasse fugir. De acordo com os registros dos processos judiciais feitos posteriormente, Henriette era obrigada a trabalhar das sete e meia da manhã até dez e meia da noite, todos os dias da semana, sem folga. Eles Ihe davam pouca comida — ela acabou ficando anêmica - e proibiam-na de falar com qualquer pessoa fora da família. Ela dormia em um colchão no chão, no quarto do bebê, e nunca recebeu pagamento.

No início, Henriette não tinha ideia da possibilidade de questionar as circunstâncias em que vivia, ou como poderia fazê-lo. Ela era intimidada pelo casal que a controlava e não conseguiu obter ajuda de um tio, a quem recorreu uma vez. A família francesa lhe dizia sempre que, por não ter papéis, por não possuir documentos, a polícia podia prendê-la se ela tentasse reclamar de sua situação.

Depois de quase quatro anos vivendo nessas condições, ela aproveitou o encontro com uma vizinha para pedir ajuda. A vizinha não tinha certeza do que poderia ser feito. Naquele ano de 1998, porém, a França celebrava 150 anos da abolição definitiva da escravidão no império francês (ocorrida em 1848) e a vizinha viu nos jornais a referência ao Comitê Contra a Escravidão Moderna. Ela contatou, então, o comitê, e a polícia apareceu na porta da família para investigar. Em 1999 iniciou-se uma sequência de processos que duraram quase tanto quanto os de Adélaïde, dois séculos antes. O julgamento da acusação contra o casal parisiense baseou-se em dois artigos do Código Penal francês (225-13 e 225-14), um que tornava ilegal extrair trabalho não remunerado ou mal remunerado de uma pessoa vulnerável ou dependente; e outro que tornava um crime sujeitar uma pessoa a condições de vida ou trabalho incompatíveis com a dignidade humana.

O juiz rejeitou a acusação de imposição de condições contrárias à dignidade humana, argumentando a insuficiência dos testemunhos para provar tal ponto. Mas condenou o casal por explorar uma pessoa vulnerável - nesse caso, menor de idade, estrangeira, cujo passaporte havia sido confiscado. O casal parisiense, senhor e senhora Bardet, foi condenado à prisão. Eles recorreram da sentença e conseguiram que ela fosse reformada, pois os juízes consideraram que Henriette não era assim tão vulnerável - eles argumentaram que, como ela falava francês, 
poderia ter usado um telefone público para pedir ajuda. Eles tomaram cada indício de mobilidade como evidência contra a acusação de exploração.

Restou apenas uma ação civil por salários atrasados, por meio da qual Henriette recebeu o valor equivalente em salários pelo tempo que trabalhou, com um complemento para recompensar seu trabalho nos dias de folga. Foi nesse ponto que o Comitê Contra a Escravidão Moderna levou o caso a julgamento na Corte Europeia de Direitos Humanos, acusando a França de falta de cumprimento do artigo quarto da Convenção Europeia de Direitos Humanos, que obriga as nações-membro a proteger as pessoas sob sua jurisdição contra a escravidão e a servidão.

É interessante observar que pareceu difícil à Corte Europeia decidir como avaliar a situação. Eles não duvidaram dos registros de trabalho não remunerado, das ameaças e do confisco dos documentos de Henriette. Mas os juízes rejeitaram o argumento de que as condições em que a moça trabalhava eram equivalentes à escravidão. Eles acharam que, para chamar isso de escravidão, teria que ter havido "um verdadeiro direito de propriedade" sobre ela, com a redução da pessoa ao estatuto de objeto.

Mas a servidão, tanto quanto a escravidão, é proibida sob o artigo quarto da Convenção Europeia, e a corte julgou o caso como sendo de servidão. A decisão final repreendeu a França por deixar de estabelecer um mecanismo, em sua legislação criminal, que estabelecesse penalidades efetivas para a ação de manter uma pessoa em servidão.

Esses dois casos mostram que, historicamente, o termo "escravo" podia referir-se tanto à condição de uma pessoa (submetida ao poder de outra pessoa) quanto ao seu estatuto (reconhecida pelo direito como propriedade). A condição de Adélaïde Métayer em Nova Orleans era de mulher livre; Louis Noret tentou mudar essa condição, argumentando que seu verdadeiro estatuto legal era de escrava. Arregimentou testemunhas que declararam ter visto Adélaïde na casa de Charles Métayer 16 anos antes, em São Domingos, e que achavam ser ela uma "escrava", nesse momento. Na república francesa em 1998, o estatuto de Henriette Akofa Siliadin era de mulher livre, porque evidentemente no século XX já não existia o estatuto de escrava. Essa mulher livre, entretanto, havia se tornado também, por meio da ação de outros, uma imigrante ilegal, vivendo numa condição de servidão. O senhor e a senhora Bardet exerceram sobre ela uma série de poderes que reconhecemos: extração de trabalho não remunerado, proibição de ir e vir com autonomia etc.

No século XIX, os advogados de Louis Noret e, em seguida, de Pierre Métayer quiseram demonstrar que havia um direito de propriedade sobre Adélaïde, herdado pelo filho do seu antigo dono, que fazia dela uma pessoa com o estatuto de escrava. Os advogados do casal parisiense no século XX, ao contrário, não quiseram e não puderam demonstrar um direito de propriedade sobre Henriette. Foi o procurador quem quis mostrar que a moça havia sido escravizada, ou sujeita à servidão, para poder culpar o casal de um crime.

É importante notar que, nos dois casos, a categorização legal da pessoa como escrava derivou da sua condição. Em 1818, a ficção legal de propriedade sobre uma pessoa foi reivindicada porque Adélaïde parece ter permanecido no poder da família Métayer quando eles moravam todos em São Domingos. A abolição que lhe conferiu liberdade formal foi ignorada. Em 2005, a condenação da França pela Corte Europeia - mesmo que o abuso de Henriette tenha sido considerado "servidão" em vez de "escravidão" - dependeu das condições a que ela foi submetida e não de seu estatuto formal. 
Então, quando confrontarmos o argumento de que a "verdadeira" definição de escravidão é "ter propriedade sobre uma pessoa" ou, nas palavras de um magistrado, ter "total sujeição do indivíduo ao poder do agente do crime", podemos responder que nem mesmo na época da escravidão legal a necessidade de provar a propriedade existiu. O exercício de um domínio senhorial é que foi considerado como evidência de que a pessoa submetida a esse domínio era escrava. O suposto "direito de propriedade" frequentemente vinha depois do exercício dos "poderes" que correspondiam a um tal direito — não o inverso.

Diante dos refugiados que desembarcaram em Nova Orleans, o prefeito da cidade designou milhares dessas pessoas como propriedade de outras milhares de pessoas, sem a menor prova de um "verdadeiro direito de propriedade." A força e a condição social foram fatos sociais, aos quais o direito logo depois deu um nome: propriedade.

Além das conclusões teóricas que podemos tirar dessas duas histórias, elas também têm epílogos. Em 1818, o processo contra Adélaïde Métayer voltou pela segunda vez à Corte Suprema da Louisiana. Pierre Métayer procurava a ajuda do Estado para que Adélaïde fosse posta em seu poder, porque ela se recusava a reconhecer que era sua escrava. Desta vez, de maneira surpreendente, o presidente da corte, respondendo aos argumentos do advogado de Adélaïde, invocou os textos sobre a escravidão codificados no tempo de Afonso, o Sábio, na Espanha medieval. Antes de a Louisiana ser um território dos Estados Unidos, tinha sido uma colônia francesa e, antes disso, uma colônia espanhola. Poder-se-ia dizer, portanto, que as cláusulas que não tinham sido explicitamente revogadas pela França ou pelos Estados Unidos ainda estavam em vigor.

A Lei das Siete Partidas considerava que a escravidão estava sujeita à prescrição, isto é, que o direito de propriedade sobre uma pessoa prescrevia, era extinto, caso não fosse exercido. Um escravo que vivesse de boa fé como livre por dez anos no mesmo país que seu senhor seria considerado livre; e um escravo que vivesse de boa fé por 20 anos em um país diferente daquele onde vivia o senhor também seria considerado livre.

O juiz na Louisiana em 1818 não reconheceu a abolição da escravidão durante a Revolução Haitiana como capaz de tornar livre uma mulher em Nova Orleans - isso teria emancipado mais de três mil pessoas e ele não poderia fazer isso. Mas ele considerou que Adélaïde tinha vivido como livre, de boa fé, desde aquela época. Se contarmos o tempo entre 1794, quando a França ratificou o decreto de abolição de São Domingos, e 1818, quando o juiz deliberou sobre o caso, são 24 anos: quatro a mais do que o necessário para julgar alguém livre com base na Lei das Sete Partidas de Afonso, o Sábio.

No final da história, a condição de Adélaïde como mulher livre - algo que ela conseguiu defender com unhas e dentes contra o alfaiate Noret - levou a uma sentença que afirmava seu estatuto jurídico de mulher livre. Ela e suas três crianças mais novas seriam, dali em diante, livres. O menino mais velho, no entanto, tinha desaparecido e sido engolido pelo mercado de escravos de Nova Orleans oito anos antes.

Felizmente, o caso de Henriette Akofa também tem um epílogo. Ela vive agora na França — casada e mãe de filhos — , com visto de residência, e trabalha como cuidadora. Agora, em 2013, a Assembleia Nacional da França está considerando uma modificação do código penal que pretende criminalizar a manutenção de uma pessoa em condições de servidão ou escravidão. 
Se essas histórias mostram a complexidade da relação entre condição social e estatuto legal, tanto no passado como no presente, também mostram a importância da consciência de direitos. Nesse sentido, somos todos herdeiros das lutas de mulheres como Adélaïde e Henriette, que mobilizaram sua própria consciência de um direito à dignidade para forçar a justiça a rejeitar que sobre elas se exercesse o que o advogado de Adélaïde chamou de "poderes ilícitos".

A definição de escravidão adotada pelo ordenamento jurídico de cada país se apoia, necessariamente, em tradições legais nacionais e pode ser mais abrangente do que aquela estabelecida no direito internacional. O artigo do código criminal francês que proíbe a imposição de condições de vida ou trabalho incompatíveis com a dignidade humana não foi suficiente para proteger Henriette Siliadin contra a escravização, em parte porque os juízes fizeram uma interpretação estreita dele. A legislação brasileira, em contraste, é baseada na combinação da garantia à dignidade humana presente na Constituição Federal de 1988, com medidas de proteção aos direitos trabalhistas já consolidadas, e assim constitui uma definição muito efetiva de trabalho escravo. A demanda por dignidade tem estado entre as principais demandas sociais dos trabalhadores em vários territórios atlânticos e conecta as lutas de hoje àquelas empreendidas sob a escravidão formal e nos anos que se seguiram à abolição. 
